\title{
Phenomenology of Postpartum Psychosis
}

${ }^{1}$ Eman M. Khedr, ${ }^{2}$ Ehab S. Ramadan, ${ }^{3}$ Mostafa A. Bastawy and ${ }^{3}$ M. Nemr Osman

${ }^{1}$ Department of Neuropsychiatry Faculty of Medicine, Asuit University, ${ }^{2}$ Department of neuropsychiatry, Faculty of Medicine, Tanta University, ${ }^{3}$ Department of neuropsychiatry, Faculty of Medicine, Aswan University Corresponding author: M. Nemr Osman, Mobile 01223341551, Email: nemrmohamed@ yahoo.co.uk

\begin{abstract}
Background For centuries, physicians have observed a temporal relation between the occurrence of female-specific reproductive events and the symptoms of illness that traditionally have been classified as "mental". Objectives: study of phenomenology of postpartum psychosis. Methods: 60 female patients with postpartum psychosis during the first four weeks after delivery (patients group) and 30 female patents within the first four weeks after delivery not suffering any psychiatric disorders (Control group). The two groups were subjected to clinical psychiatric assessment using structured psychiatric interview of DSM -V, BPRS, HDRS and EPDS. Results: Postpartum psychosis was more in younger females than older and in primipara than multipara. The onset of symptoms of postpartum psychosis was more common in first week after delivery (mean 6.11 days), sleep disturbance, irritability and hypomanic symptoms are the most early symptoms of postpartum psychosis followed by anxiety, confusion and somatic complain. Mood congruent psychotic feature significantly more than mood non-congruent psychotic feature. Conclusion: postpartum psychosis is more common in younger and primipara females with onset of symptoms in first in first week after delivery. Sleep disturbance, irritability and hypomanic symptoms are the earliest symptoms of postpartum psychosis.
\end{abstract}

Keywords: Phenomenology of postpartum psychosis.

\section{INTRODUCTION}

For centuries, physicians have observed a temporal relation between the occurrence of femalespecific reproductive events and the symptoms of illness that traditionally have been classified as "mental". Obviously, psychiatric disorders occurred during maternity leave still occupies a territory and a period of time unrecognized in their entirety mean some, others controversial, the plan nosologic, etiopathogenetic and psychopathology ${ }^{1}$. The normal postpartum period consists of physical exhaustion, sleep deprivation and dramatic changes in hormones and electrolytes balance. This challenge can provoke a wide variety of psychiatric disorders, of which postpartum psychosis is the most severe ${ }^{2}$.

Postpartum psychosis occurs in 1 to 2 of every 1000 new mothers. If undetected and untreated, postpartum psychosis presents a danger to both the life of the mother and her infant. Infanticide is rare but does occur in 1 of 250,000 women with postpartum psychosis ${ }^{3}$. The clinical picture of postpartum psychosis is often a combination of clouding consciousness and affective symptoms, hallucinations, confusion, perplexity and sleepiness are common. Characteristic is the rapid change from normality to fully developed syndrome. All most all psychotic symptoms have been described among women with puerperal psychosis in the literature: megalomania concerning the identity of the child, delusions about the child being a changeling, paranoia, verbal hallucinations, though insertion, thought broadcasting, echo phenomena, mania and catatonia ${ }^{4}$. It appears that postpartum psychosis is most likely to be a variant of bipolar disorder rather than a discrete subtype of psychotic illness ${ }^{5}$.

\section{AIM OF THIS WORK}

Study of phenomenology and clinical variables of postpartum psychosis within four weeks after delivery which help in early diagnosis of this disorder

\section{SUBJECTS AND METHODS}

This study was carried out at the out-patient clinic of Neuropsychiatry Department, the out-patient and inpatient of Gynecological and Obstetric Department of Aswan University Hospital. The study was carried out from January 2016 to January 2017. The subjects of this study were females in postpartum period within four weeks after delivery with age ranged from 16 years to 32 years.

\section{Ethical approval:}

The study was approved by the Ethics Board of Aswan University and an informed written consent was taken from each participant in the study.

The subjects were grouped into:

Group I (Patients group): Included 60 females with first-onset psychiatric illness developed in the first four weeks after delivery.

Exclusion criteria: Patients with established neurological disorders and severe physical illness, patients with past history of reported psychiatric illness, patients on hormonal preparations for endocrinal disturbance or any causes, patients with chronic medical illness as renal or hepatic illness, and patients with history of head trauma and epilepsy.

Group II (Control group): Included 30 females in the first four weeks after delivery.

Exclusion criteria: Females suffering from any psychiatric illness in addition to the same exclusion 
criteria in group I. Approval of the Ethical Committee and consent of the patients were taken.

The two groups were subjected to: 1 . Clinical study: Thorough clinical psychiatric examination and clinical assessment by structured psychiatric interview of DSM$\mathrm{V}^{6}$.

2- Psychometric Assessment included Hamilton Rating Scale for depression (HAM-D OR HDRS), ${ }^{7}$ Brief Psychiatric Rating Scale (BPRS) Expanded Version $^{8}$ and Edinburg Postnatal Depression Scale $(\text { EPDS })^{9}$.

Statistics: Statistical presentation and analysis of the present study was conducted, using the mean and standard deviation. Unpaired Student Ttest was used to compare between two groups in quantitative data and chi-square was used to compare qualitative data. IBM SPSS Statistics for Windows, Version2 0.0. Armonk, NY: IBM Corp, was used. P values were considered as follows:- $>0.05$ Non significant, $<0.05^{*}$ significant $<0.001^{* *}$ Highly significant

\section{RESULTS}

This study demonstrated that: there was significant difference regarding the mean age of patients of postpartum psychosis (Table 1).

Table (1): Comparison between mean age of patients and controls.

\begin{tabular}{|c|c|c|c|}
\hline & $\begin{array}{c}\text { Patients } \\
(\mathbf{n}=60)\end{array}$ & $\begin{array}{c}\text { Controls } \\
(\mathbf{n}=\mathbf{3 0})\end{array}$ & P-value \\
\hline Mean age & 19.2 & 24.7 & \multirow{2}{*}{$<0.001 * *$} \\
\hline SD & \pm 2.7 & \pm 1.2 & \\
\hline
\end{tabular}

Postpartum psychosis was significantly more in primipara than multipara females (table 2).

Table (2): Parity in both patients and controls.

\begin{tabular}{|l|c|c|c|c|c|}
\hline \multirow{2}{*}{} & \multicolumn{2}{|c|}{$\begin{array}{c}\text { Patients } \\
(\mathbf{n = 6 0})\end{array}$} & \multicolumn{2}{c|}{$\begin{array}{c}\text { Controls } \\
(\mathbf{n = 3 0})\end{array}$} & \multirow{2}{*}{ P-value } \\
\cline { 2 - 5 } & No. & $\mathbf{\%}$ & No. & \% & \\
\hline Primipara & 44 & 73.3 & 14 & 46.7 & \multirow{2}{*}{$0.013 *$} \\
\hline Multipara & 16 & 26.7 & 16 & 53.3 & \\
\hline
\end{tabular}

The mean day of onset of postpartum psychosis was 6.11 days $\pm-\mathrm{SD} \pm 1.62$ and the prevalence of mood congruent psychotic symptoms $(58.3 \%)$ was higher than the mood incongruent psychotic symptoms (41.7\%). Early symptoms of postpartum psychosis in patients group were sleep disturbance (66.7\%), irritability (65\%) and hypomanic symptoms (56.7\%) were the most early symptoms of postpartum psychosis followed by anxiety (58.3\%), confusion $(33.33 \%)$ and somatic complain $(30 \%)$.
Postpartum psychosis with manic psychotic feature was in $58.3 \%$ of patients, followed by postpartum psychosis with depressive psychotic feature in $16.7 \%$ of patients, followed by postpartum psychosis with depressive and manic feature in $13.3 \%$ of patients and postpartum psychosis with only psychotic feature in $11.7 \%$ of patients.

There were higher significant difference regarding the mean score of Brief Psychiatric Rating Scale (BPRS), Hamilton Depression Rating Scale (HDRS), and Edberg Postnatal Depression Sale (EPDS) between patients and controls (Table 3).

Table (3): Mean score of BPRS, HDRS and EPDS in patients and controls.

\begin{tabular}{|c|c|c|c|}
\hline & $\begin{array}{l}\text { Patients } \\
(\mathbf{n = 6 0}) \\
\text { Mean }\end{array}$ & $\begin{array}{l}\text { Controls } \\
(\mathbf{n = 3 0}) \text { Mean }\end{array}$ & P-value \\
\cline { 4 - 4 } & SD \pm & SD \pm & \\
BPRS & 76.2 & 24.2 & \\
& 1.2 & 2.0 & $<0.001^{* *}$ \\
HDRS & 12.6 & 5.33 & \\
& 1.9 & 2.41 & $<0.001^{* *}$ \\
EPDS & 14.2 & 4.7 & $<0.001^{* *}$ \\
& 2.91 & 1.2 & \\
\hline
\end{tabular}

\section{DICUSSION}

In this study the mean age of patients was $19.2-\mathrm{SD} \pm 2.7$ years while in controls it was $24.7-\mathrm{SD}$ \pm 1.2 years, this difference was statistically significant which means that young mothers are at high risk for developing postpartum psychosis than older mothers. This result was in agreement with Kumar et a1. ${ }^{10}$ India. In contrast Valdmirsdottir et al. $^{11}$ and an Egyptian study on 26 female patients with postpartum psychiatric disorders done by Abdel Latif et al. ${ }^{12}$ reported postpartum psychosis was more liable to occur above the age of 30 years.

The result of this study showed higher significant difference regarding primiparity in patients with postpartum psychosis than controls, which contributed that primiparity was associated with a higher risk for postpartum psychosis. Also the same finding was observed by Kumar et al. ${ }^{10}$, Kirpinar et al. ${ }^{13}$, Bergink et al. ${ }^{14}$, Ndosi ${ }^{15}$, Robertson et al. ${ }^{16}$, and Lusskin et al. ${ }^{17}$. In this study the mean onset of symptoms of postpartum psychosis was in the first week (6.11 days). This was in agreement with Valdkmirsdottir $^{11}$, Ndosi ${ }^{15}$, and Hay ${ }^{18}$ who reported most of their patients with postpartum psychosis had onset of symptoms within the first week after delivery, even Brockington ${ }^{19}$ reported early cases of postpartum psychosis on the first day after delivery. However, many other studies by Bergink et al. ${ }^{14}$, Lusskin et 
al. ${ }^{17}$ and Monzon $\boldsymbol{e t}$ al..$^{20}$ reported the onset of symptoms of postpartum psychosis to be more common within the second week after delivery. Another study in turkey by Kirpinar et al. ${ }^{13}$ reported the mean onset of postpartum psychosis within the $4^{\text {th }}$ week after delivery. The results of this study showed that the incidence of mood congruent delusions (58.3\% of patients) was more common than the mood non-congruent delusions (41.7 $\%$ of patients); this was in agreement with the finding of Lusskin et al. ${ }^{17}$.

In contrast to this finding, Bergink et al. ${ }^{14}$ and Monzon et al. $^{20}$ reported mood non-congruent delusions were more common than mood congruent delusions in patients with postpartum psychosis. In this study nearly sixty percent of women reported experiencing prodromal changes very early in the postpartum period (from the first day), prior to onset of frank psychosis. Those symptoms were in the form of hypomanic symptoms $(56.7 \%)$ confusion $(33.33 \%)$, irritability $(65.5 \%)$, sleep disturbance $(66.7 \%)$, anxiety $(58.3 \%)$ and somatic complain (30\%).

Kamperman et al. ${ }^{21}$ reported irritability to be one of the most early and prominent feature of postpartum psychosis. The same results were reported by Heron et al. ${ }^{22}$ who studied the early symptom of postpartum psychosis in one hundred and twenty seven women with puerperal psychosis within four weeks after delivery.

Also the findings of this study were consistent with prospective study description of prodromal signs of postpartum psychosis by Prothero ${ }^{23}$ Sharma $^{24}$ who reported rapid mood fluctuation, excitement, insomnia, restlessness, exhaustion, sleep disturbance and irritability as early symptoms of postpartum psychosis. This study reported that 35 out of $60(58.3 \%)$ patients had postpartum psychosis with manic psychotic feature, 7 out of $60(11.7 \%)$ patients had postpartum psychosis with only psychotic feature, 10 out of 60 $(16.7 \%)$ patients had postpartum psychosis with depressive psychotic feature and 8 out of 60 (13.8\%) patients had postpartum psychosis with depressive and manic feature, so the majority of patients had bipolar symptoms.

This was in agreement with Bergink et al. ${ }^{14}$ in a study of 51 women with first-onset postpartum psychosis as they reported that: $62.6 \%$ of their patients had postpartum psychosis with manic psychotic feature, $7.8 \%$ of patients had postpartum psychosis with only psychotic feature, $13.7 \%$ of patients had postpartum psychosis with depressive psychotic feature and $7.8 \%$ of patients had mixed manic and depressed feature. On the other hand Kamperman et al. ${ }^{21}$ reported manic feature in $34 \%$, depressive feature in $41 \%$, and atypical feature in $25 \%$ of their patients of postpartum psychosis.

In this study Brief Psychiatric Rating Scale (BPRS) was used in the assessment of symptoms in patients with postpartum psychosis. The mean score of Brief Psychiatric Rating Scale (BPRS) in patients with postpartum psychosis was $76.2 \pm 4.9)$ which was significantly higher than controls $(18.2 \pm 2.0)$.

This was in agreement with Thippeswamy et $\boldsymbol{a l} .^{25}$ who reported higher significant score of BPRS in patients with severe postpartum mental illness. In this study there was higher significant difference regarding the score of Hamilton Depression Rating Scale (HDRS) between patients with postpartum psychosis and controls.

This was in agreement with Kamperman $\boldsymbol{e t}$ $\boldsymbol{a l} .^{21}$ who reported variable degrees of depressive symptoms in most of their patients than controls. Also, this was in agreement with Jones et al. ${ }^{26}$, Bergink et al. ${ }^{27}$ and Lusskin et al. ${ }^{17}$ who claimed the prevalence of mild to moderate depression in patients with postpartum psychosis.

Regarding Edinburg Postnatal Depression Scale (EPDS) there was higher significant difference between the mean score of EPDS in patients of postpartum psychosis and controls. This study reported 25 out of 60 patients of postpartum psychosis $(41.66 \%)$ had score 10 or more (possible depression) and 35 out of $60(58.33 \%)$ patients with postpartum psychosis had normal score (9 or less). This was in agreement with the findings of Benvenuti et al. ${ }^{28}$ who reported depression to be more common in patients with postpartum psychosis and he also claimed that almost of patients with postpartum have depressive affective disorders.

\section{REFERENCES}

1. Lewis G (2007): The Confidential Enquiry into Maternal and Child Health (CEMACH): Saving Mothers' Lives: Reviewing Maternal Deaths to Make Motherhood Safer 2003-2005. The Seventh Report on Confidential Enquiries into Maternal Deaths in the United Kingdom. https://www.ncbi.nlm.nih.gov > pmc > articles

2. Zhong Q, Gelay B, Fricchione G, Lllivance et al. (2018): The global prevelance of postpartum psychosis among pregnant women .BMC Pregnancy Chiled birth, 18:1750-0.

3. Vanderkraik R, Barreix M (2017): The global prevelance of postpartum psychosis: A systemic review. BMC. Psychiatry, 17:272.

4. Jones I, Craddock N (2014): Bipolar disorder, affective psychosis and schizophrenia in pregnancy and postpartum peroid. Lanct, 384:1789-1799.

5. Kendell RE, Chalmers JC, Platz C (1987): Epidemiology of puerperal psychosis. Britich Journal of psychiatry, 150: $662-73$.

6. American Psychiatric Association 2013 (2013); Available from: http://www.dsm5.org/Pages/Default.aspx.

7. Hamilton M (1960): Rating scale for depression. Psych. Neurol. Neurosurg., 23:56-62. 
8. Kopelowicz A,Ventra J (2008): Consistency of Brief Psychiatrc Rating Scale Rating structure across abroad spectrum of schizophrenic patients. Psychathology, 41:7784.

9. Cox JL, Holden JM, Sagovesky R (1987): Detection of postnatal depression. Development of the 10 items depression postnatal scale Britch. J. Psychiatry, 30,:361:70 .

10.Kumar S, Sharma A, Raval C (2014): Postpartum psychosis: risk factors identification. N AM L Med. Sci., 6(6):264-277.

11. Valdkmirsdottir M, Hultman C, Harlow B et al. (2009): Psychotic in first-time mothers with no previous psychiatric hospitalizations a: A population- based study. pLo. S med., 6(2): 13.

12. Abdel Latif A , Amany A, Yoysry A(2010): Postpartum psychiatric disorders in outpatient setting) master thesis, Cairo University.

13. Kirpinar I, Coskun I ,Caykoylu A (1999): First-case post-partum psychosis in Eastern Turkey: A clinical case and follow-up study. Acta Psychiatr Scand., 100:199.

14.Bergink V, Lambregtsevan $M$, Koorengevel $K$ et al. (2011): First-onset psychosis occurring in the postpartum period: a prospective cohort study. J. Clin. Psychiatry,72:1531-1537.

15. Ndosi N K (2002): The nature of puerperal psychosis at Muhimbili national hospital: its physical co-morbidity associated main obstetric and social factors. African Journal of Reproductive health, 1(6): 41-49.

16. Robertson E, Jones I, Haque $S$ et al. (2005): Risk of puerperal and non- puerperal recurrence of illness following bipolar affective puerperal (post-partum): psychosis. British Journal of Psychiatry, 186: 258-9.
17.Lusskin S, Stefen M, Richard H (2011): Postpartum psychosis; Epidomiology clinical manifestations and assessment. Up Todate inc. Relese, 25:2-12.

18. Hay P J (2009): Postpartum psychosis: which women at high risk? PLoS Med., 6(2): 100-127.

19. Brockington IF (2017): Non-reproductive triggers of postpartum psychosis. Arch Women Mental Health, 20:71-76.

20. Monzon C, Scalea T, Pearlstein T (2014): Postpartum psychosis: updates and clinical issues. Psychiatric times, 31(1):26-28.

21. Kamperman A, Veldman H, wesselook J (2017): phynotypal charchterstics of postpartum psychosis. Bipolar Disorder, 19:450-457.

22.Heron J, McGuinness M, Robertso B et al. (2007): Early symptoms in puerperal psychosis. An International journal of obstetric and gynecology, 37:147-52.

23.Protheroe C (1969): Puerperal psychosis: A long term study 1927-1961. British Journal of Psychiatry, 11(518): 9-30.

24. Sharma V (2003): Role of sleep loss in the causation of puerperal psychosis. Med. Hypothese, 61(4)477-81.

25. Thippeswamy H, Desai G , Chndru P (2018): Helpseeking pattern in women with postpartum severe mental illness. Arch Women Mental Health, 51:573-578.

26.Jones I and Smith C (2009): Puerperal psychosis: identifying and caring for women at risk. Advances in Psychiatric treatment, (15):411-418.

27. Bergink V, Rasqon N , Wisner K (2016):Postpartum psychosis: madness, mania and melanocholia.am. J. Psyciat., 137(12):1175-1188.

28. Benvenuti P, Cabras P, Servi P (1992): Puerperal psychoses: A clinical case study with follow-up. J. Affective 